\title{
Coupled Lateral-Torsonal Vibration Analysis of a Geared Shaft Rotor System using a Complex Rotor Variable Approach
}

\author{
K. V. S. Seshendra Kumar \\ Department of Industrial Production Engineering, GITAM Institute of Technology, GITAM University, \\ Visakhapatnam-533045, Andhra Pradesh, India
}

B. S. K. Sundarasiva Rao

Department of Mechanical Engineering, Andhra University College of Engineering, Visakhapatnam-530003, Andhra Pradesh, India

(Received 10 October 2010; Provisionally Accepted 15 February 2012; Accepted 14 May 2012)

Though there have been numerous studies on both rotor dynamics and gear dynamics, the studies on geared rotor dynamics have been rather recent. The study of the dynamic behavior of geared rotor systems usually requires that torsional and lateral vibration modes be coupled in the model, a problem not present for studies of rotors without gears. For rotor dynamics studies, the finite-element method seems to be a highly efficient modeling method. In the present work, a finite-element model of a geared rotor system on flexible shaft bearings has been developed. The whirling motion and critical speed of the system has to be found by considering all the rotors in the system as well as interactions between them. It is shown that the lateral vibrations have considerable effect when the natural frequencies of the lateral vibration and torsional vibration are close to each other, which is well expected. By studying the responses of the system with strong lateral-torsional coupling, the nature of the coupling effect is discussed.

\section{INTRODUCTION}

The study of dynamic behavior of geared rotor systems usually requires that torsional and transverse vibration modes be coupled in the model, a problem not present for studies of rotors without gears. Early geared rotor dynamic models concentrated on the effects of mass imbalance and eccentricity of the gear on the shaft, virtually neglecting the actual dynamics of gear mesh. Mitchell and Mellen ${ }^{1}$ included lateral vibration of the shafts and their bearings in their models.

In their study, they considered the coupled vibration of shaftbearing systems through experimental models. ${ }^{2}$ included influence coefficients at each gear mesh by using the Holzer method for torsional vibrations and the Myklestad-Prohl method for lateral vibrations, thus obtaining critical speeds and a forced vibration response.

The backlash detection and its influence in geared systems have been studied by Sarkar et al. ${ }^{3}$ Ambili and Fregolent ${ }^{4}$ determined modal parameters of spur gear systems using the harmonic balance method. A study of designing compact spur gears, taking into consideration tooth stress and dynamic response, was conducted by Lin et al. ${ }^{5}$ The dynamic behavior of spur gears to varying mesh stiffness and tooth error has been studied by Kuan and Lin. ${ }^{6}$ A mathematical model for gear geometry errors and mounting errors has been developed by Velex and Maatar. ${ }^{7}$ Theodassiades and Nastiavas $^{8}$ studied the nonlinear behavior of gear systems with backlash and varying stiffness. Theodassiades and Nastiavas also studied the nonlinear influence of bearings characteristics on gear pair systems. ${ }^{9}$ A modal analysis of compliant multibody gear systems has been carried out by Vinayak and Singh. ${ }^{10}$ Shen et al. ${ }^{11}$ per- formed coupled torsional-lateral vibration of the unbalanced rotor system with external excitations through numerical simulation.

Rotating shafts tend to bow out and whirl at certain speeds called the critical speed or whirling speed. Various factors that can cause the shaft to whirl are mass unbalance of the rotating system, gyroscopic forces, unsymmetrical stiffness, etc. Studies of whirling of rotor systems can be found in the literature. ${ }^{12-14}$ They have conducted studies on the dynamics of rotors and discussed related assumptions. Modal analysis of undamped rotor systems and the gyroscopic effect of rotors has been studied by many researchers, including Wang and Kirkhope, ${ }^{15}$ Dutt and Bakra, ${ }^{16}$ and Genta and Tonoli. ${ }^{17}$ The gyroscopic effect is what couples the forward and backward modes of rotors, as discussed by Kessler and Kim. ${ }^{18}$ For geared shaft systems, however, the torsional and lateral vibrations are generally coupled because the forces acting on the gears and the motion of the elements in one direction have influence in other directions. It has been demonstrated by Neriya et al. ${ }^{19}$ and Iida et al. ${ }^{20}$ that the predicted dynamic behavior of a geared shaft system, taking into account this cross coupling, could be different from that obtained using a conventional model of the system. Schwibinger and Nordamann ${ }^{21}$ studied the coupling effect between torsional and flexural vibrations in a geared rotor system that can affect the stability of the system and influence, for example, the stability threshold and damping constants in oil film bearings. It has been shown that the classical eigenvalue analysis, which ignores the coupling of torsional and flexural vibrations in gears, may lead to serious errors in the prediction of the stability onset speed, the critical speeds, and the natural modes. 